3 Brismar B, Peterson H, Tokics L, Strandberg A, Hedenstierna $G$. Postoperative analgesia with intrapleural administration of bupivicaine-adrenaline. Acta Anaesthesiol Scand 1987; 31: 515-20.

4 Aguilar JL, Montero A, Vidal Lopez F, Llamazares

$J F$. Bilateral interpleural injection of local anesthetics. Regional Anesthesia 1989; 14: 93-4.

\section{A nontraumatic induction technique for paediatric patients}

To the Editor:

Induction of anaesthesia is frequently a traumatic and frightening experience for young children. The standard technique of inhalational induction for paediatric patients is often a struggle due to separation from parents, a fear of suffocation, and the unpleasant smell of the inhalational agent. Various methods of premedication and induction have been suggested to alleviate these problems. ${ }^{1-3}$

An induction technique that I have found useful in the four- to eight-yr-old range involves having the child interact with the capnograph. I ask the child to hold the mask tightly on his face, take a deep breath and exhale while watching the monitor. Usually children induced in this manner are quite pleased when they discover that they have made a "bump" on the monitor. I ask the child to try to make "big bumps", "little bumps", "multiple bumps" in a row, while counting with me. While they are doing this I start with high flows of nitrous oxide $\left(7 \mathrm{~L} \cdot \mathrm{min}^{-1}\right)$ and oxygen $\left(3 \mathrm{~L} \cdot \mathrm{min}^{-1}\right)$ and gradually introduce an inhalational agent, usually halothane.

This technique helps to distract the child while facilitating the induction of anaesthesia. Because the child has some control over the situation, the induction turns out to be a pleasant and nontraumatic experience.

\section{P.L. Steer MD}

Department of Anesthesiology

University of Kansas

Medical Center

Kansas City, Kansas

\section{REFERENCES}

1 Smerling A, Delphin E. A new device to smooth pediatric inhalation induction. Anesth Analg 1986; 65: 1366-70.

2 Nicolson SC, Betts EU, Jobes DR et al. Comparison of oral and intramuscular preanesthetic medication for pediatric inpatient surgery. Anesthesiology 1989; 71: 8-10.

3 Henderson JM, Brodsky DA, Fisher DM, Brett CM, Herzza RE. Pre-induction of anesthesia in pediatric patients with nasally administered sufentanil. Anesthesiology 1988; 68: 671-5.

\section{Research Development Day}

To the Editor:

The Department of Anaesthesia at UBC has developed a program to encourage and improve clinical research. "Research Development Day" started in 1988 and is offered to all residents and faculty. The aim of the program is to offer guidance in developing the skills necessary to initiate and complete research and to improve written and oral presentation. The morning of the program is devoted to didactic lectures by three to four speakers which is followed by afternoon workshops. The afternoon workshops are designed so that each participant spends a portion of the time with each facilitator. Lecturers are chosen who are dynamic speakers and enthusiastic about their field. Flexibility is another essential attribute as they have to adapt to the needs of the participants. Speakers have been drawn from the faculties of Anaesthesia, Epidemiology, Pharmaceutical Sciences, Computer Science, Library Science and from the UBC Clinical Screening Committee for Research Involving Human Subjects. Each of the speakers contributes a written handout which is given to the registrants.

The topics covered in the first year consisted of (1) getting started in research; (2) writing for publication; and (3) slide-making and oral presentation. The afternoon workshop on the first topic consisted of designing a clinical research project. The workshop on writing examined abstracts which were critiqued by the group. The third workshop utilized resident presentations which had been prepared for the annual residents' competition. These oral presentations and the slides were analyzed and suggestions for improvements were made.

The second year was designed to expand on these topics and included: (1) the ethics of research; (2) using the library; (3) statistics; and (4) writing a grant application. The workshops followed a similar format with hands-on experience for the participants.

The theme for the third year was Computers in Research and the topics included: (1) the use of computers for research; (2) the types of computers for research needs; (3) word processing; and (4) computer use for statistics and graphic aids. The afternoon workshop was held in a computer laboratory where each participant had 
access to a computer, practiced editing a paper (using a word processing program) and finally, used a computer statistical package to determine the significance of research data.

Other departments who wish to expand their clinical research programs may find this type of program useful.

\author{
M. Joanne Douglas, MD FRCPC \\ Leonard C. Jenkins, MD FRCPC \\ Department of Anaesthesia \\ University of British Columbia and Grace Hospital \\ Vancouver, British Columbia, Canada
}

\section{Phaeochromocytoma presenting as $M H$}

To the Editor:

We would like to make a few remarks concerning diagnostic and therapeutic approaches in the recently published case report by Allen and Rosenberg. '

First, in the Discussion, there should be some mention of the possibility that the massive sympathetic discharge which occurred immediately after induction might be the result of carbon dioxide retention in a patient receiving deep anaesthesia and breathing spontaneously with a mask. Furthermore, the respiratory acidosis and hypoxaemia were treated with intravenous sodium bicarbonate instead of hyperventilation. Sodium bicarbonate dissociates in plasma and increases plasma carbon dioxide concentration and worsens respiratory acidosis.

The patient did not receive prophylactic dantrolene before adrenalectomy which conflicts with the authors' suspicion of malignant hyperpyrexia, reflected by avoidance of known MH triggers and by performing specific MH testing six months later.

The use of prophylactic dantrolene in susceptible patients is controversial. Some authors advise using prophylactic iv dantrolene shortly before surgery, in susceptible or highly susceptible patients ${ }^{\mathbf{2 . 3}}$ whereas others avoid it because of dantrolene's side-effects. ${ }^{4.5} \mathrm{We}$ believe that it is easier to ventilate the lungs of a patient with dantrolene-induced muscle weakness than to treat malignant hyperthermia.

\author{
Tiberiu Ezri MD \\ David Soroker MD \\ Department of Anaesthesiology \\ Kaplan Hospital \\ 76100 Rehovot \\ Israel
}

\section{REFERENCES}

1 Allen GC, Rosenberg $H$. Phaeochromocytoma presenting as acute malignant hyperthermia - a diagnostic challenge. Can J Anaesth 1990; 37: 593-5.

2 Flewellen EH, Nelson TE, Jones WP, Arens JF, Wagner $D L$. Dantrolene dose response in awake man: implications for management of malignant hyperthermia. Anesthesiology 1983; 59: 275-80.

3 Rosenberg $H$, Seitman D. Pharmacogenetics. In: Barash PG, Cullen BF, Stoelting RK. Clinical Anesthesia. J.B. Lippincott Co. Philadelphia, 1989.

4 Gronert GA, Shulman SR, Mott J. Malignant hyperthermia. In: Miller RD (Ed.). Anesthesia, 3rd ed., Churchill Livingstone Inc., 1990; 950-1.

5 Hackle W, Mauritz W, Winkler M, Sporn P, Steinbreithner $K$. Anaesthesia in malignant hyperthermia - susceptible patients without dantrolene prophylaxis: a report of 30 cases. Acta Anaesthesiol Scand 1990; 7: 535-8.

\section{REPLY}

We should state at the outset that the patient described in our case report was referred to us from another hospital. Caffeine halothane contracture testing was performed at our institution six months after the acute episode. Therefore, it would be inappropriate for us to try to second-guess those involved in the management of the patient.

We cannot comment on the possibility of $\mathrm{CO}_{2}$ retention triggering the hypermetabolic episode. There is no evidence to suggest this in the records from the other hospital. We agree that respiratory acidosis is most effectively treated with hyperventilation. However, it is also important to remember that these anesthetists were faced with an unusual, but life-threatening hyperadrenergic crisis, which carries a high mortality. Because of their management, the child survived.

Finally, we acknowledge that the use of prophylactic dantrolene is controversial. Like any intervention, the benefit must be weighed against the risk of side-effects and the additional cost incurred. Although dantrolene may reduce the risk of an $M H$ episode, the degree of risk reduction is not known.

Gregory C. Allen MD

Ottawa Civic Hospital

Henry Rosenberg MD

Department of Anesthesiology

Hahnemann University,

Philadelphia

\section{The laryngeal mask airway in children}

To the Editor:

The laryngeal mask airway (LMA) has a useful place in anaesthetic practice in adults. We report a study carried 